\title{
Effect of Acute Exercise on Plasma Nitric Oxide Level in Humans
}

\author{
L. Franco ${ }^{a}$ D. Doria ${ }^{a}$ F. Mattiuccib \\ a Institute of Pharmacology, Faculty of Medicine, University of Verona, Policlinico Borgo Roma, and \\ bIstituto Superiore di Educazione Fisica of Verona, Italy
}

\section{Key Words}

Nitric oxide $\cdot$ Plasma $\cdot$ Exercise $\cdot$ Training $\cdot$ Men

\begin{abstract}
Objective: Since nitric oxide (NO) plays an important role in regulating vascular tone and changes in the plasma concentration of the end product of NO (nitrite/nitrate) have been observed during exercise, we studied the influence of acute exercise on nitrite/nitrate plasma levels in a group of semiprofessional football players and in younger and older sedentary subjects. Methods: The subjects exercised for $10 \mathrm{~min}$ on a cycle ergometer and blood samples were obtained at rest and immediately after exercise. Plasma samples were analysed for nitrite/ nitrate. Results: The acute physical exercise induced a significant increase in nitrite/nitrate plasma levels both in sedentary and in active subjects. No difference was evident between the younger and older subjects, both in the basal level and after exercise, indicating that the changes could not be due to age. The higher basal plasma level of nitrite/nitrate observed in the active subjects compared with sedentary groups indicates that the state of physical conditioning had an effect on resting NO concentration. Conclusion: It seems that either acute exercise, even for a short time, or training can induce an increase in circulating NO.
\end{abstract}

Copyright $@ 2001$ S. Karger AG, Basel

\section{Introduction}

Nitric oxide (NO) derived from the vascular endothelium and other cells has important roles in the physiological regulation of blood flow and may have pathophysiological functions in cardiovascular disease. Two general classes of stimuli have been found to elicit release of endothelial NO: pharmacological stimuli such as norepinephrine, acetylcholine and bradykinin and physical stimuli such as shear stress or some distortional force on the blood vessel wall. Both of these general classes of stimuli increase intracellular calcium concentration in the endothelial cells [1]; the increase of calcium, in turn, leads to activation of constitutive NO synthase [2]. Following the stimulating of the constitutive endothelial NO synthase, NO diffuses to the underlying vascular smooth muscle to activate guanylate cyclase [3], resulting in vasodilation. During exercise vasodilation is observed in the systemic arteries, but the factors contributing to the mechanism are controversial. An increase in cardiac output during exercise causes a rise in shear stress which could trigger NO production. A number of studies performed on animals provide evidence that supports the contention that NO contributes to exercise hyperaemia $[4,5]$ and that it may coordinate the vascular response to exercise [6]. However, studies performed in humans are conflicting, some supporting [7-9] and others rejecting $[10,11]$ the involve-

L. Franco

Institute of Pharmacology, Faculty of Medicine

University of Verona, Policlinico Borgo Roma

I-37134 Verona (Italy)

Tel. +39045 8027604, Fax +39045 581111, E-Mail luigina.franco@univr.it 
ment of NO in the acute hyperaemic response to exercise. Similarly, the influence of exercise training on endothelial NO response remains controversial. Although studies performed in animals provide evidence in favour of $\mathrm{NO}$ modulation, there are few studies which have been performed in humans, and those that have been conducted are contradictory [12-14].

The aim of the present study was to investigate changes in the plasma concentration of NO in systemic blood in response to acute physical exercise in younger and older sedentary subjects and whether physical conditioning induced by a repetitive exercise stimulus would elicit changes in NO synthesis. For this purpose we determined changes in the plasma concentration of NO in response to acute physical exercise in younger sedentary volunteers, in older sedentary men, and the same parameters in a group of semiprofessional football players were studied for comparison of their basal levels during training with those of the sedentary groups.

\section{Materials and Methods}

\section{Characteristics of the Subjects}

For this study three groups have been considered. The first group consisted of athletes who were male football players $(n=8$; median age 22; range $17-25$ years) belonging to a semiprofessional team. The training programme of the team consisted of one daily training session (90-120 min) 4 times a week with one competition on Sundays. The training programme consisted of aerobic (endurance running) and anaerobic (intense short-distance running) exercise. The second group consisted of younger sedentary males $(n=12$; median age 22; range 18-27 years), and the third group of older sedentary males $(\mathrm{n}=$ 10 ; median age 66; range 58-72 years). All subjects had no evidence of present or past hypertension, hypercholesterolaemia, or cardiovascular disease. The characteristics of active subjects and sedentary subjects did not differ significantly. All subjects were kept on a nitrate low diet for 3 days before the test. The study was performed in the morning, after the intake of a light breakfast, in a quiet air-conditioned room that was maintained at a constant temperature (22$24^{\circ} \mathrm{C}$ ). Informed consent was obtained from all subjects.

\section{Exercise}

The study protocol constituted a bicycle ergometer exercise test. The subjects began exercise at a workload of $25 \mathrm{~W}$, which was increased in stepwise increments until submaximal conditions, when the heart rate attained $80 \%$ of the maximal rate. This exercise intensity was then maintained for $10 \mathrm{~min}$. Systolic blood pressure and heart rate were recorded immediately before and after exercise. Peripheral venous blood samples were drawn by antecubital venipuncture immediately before exercise and immediately after the acute physical exercise. Blood was collected into sterile heparinized tubes and centrifuged for $5 \mathrm{~min}$ at $2,000 \mathrm{~g}$ at $4{ }^{\circ} \mathrm{C}$. Plasma samples were analysed for nitrite/nitrate $\left(\mathrm{NO}_{2}^{-} / \mathrm{NO}_{3}^{-}\right)$, the major metabolite of NO. Nitrite accumulation in the plasma was determined by first reducing the nitrate using a bacterial nitrate reductase prepared from Escherichia coli ATCC 25922. Nitrite was assayed colorimetrically after reaction with the Griess reagent [15]. The absorbance was evaluated with a microplate reader (Argus 400, Canberra Packard) at $550 \mathrm{~nm}$ (OD 550). All measurements were performed in duplicate. The intra- and interassay variations were 6.9 and $8.4 \%$, respectively.

\section{Statistics}

All the data are expressed as mean $\pm \mathrm{SD}$. The statistical significance of the difference between groups was determined by one-way analysis of variance followed by Bonferroni $t$ test. A probability $(p)$ value of 0.05 or less was taken to indicate statistical significance.

\section{Results}

The age, weight, and height of the subjects are presented in table 1. Clinical history, physical examination, electrocardiogram and routine laboratory tests showed that these subjects had no evidence of present or past hypertension, hypercholesterolaemia or cardiovascular disease. All subjects presented the same characteristics, were nonsmokers, did not consume alcoholic beverages, and none had any symptom of illness or infection or had taken drugs at the time of the study.

The values of the end products of NO from the football players, the younger and the older sedentary subjects before and after acute exercise test are shown in table 2 . In the sedentary subjects the age did not modify significantly the basal levels of plasma $\mathrm{NO}_{2}^{-}$(younger $23.78 \pm 5.74$; older $22.17 \pm 6.14$ ). In contrast, we observed significantly higher basal levels of plasma $\mathrm{NO}_{2}^{-}$in the athletes compared to the sedentary subjects $(41.40 \pm 6.06 ; p<0.001)$. The acute exercise test induced significant changes in nitrite concentrations of systemic venous blood whether in active or inactive subjects. Production of $\mathrm{NO}_{2}^{-}$during exercise was more pronounced in active subjects, even if not significantly compared to inactive subjects. No difference was found in $\mathrm{NO}_{2}^{-}$concentrations after the acute exercise test in the younger sedentary subjects and the older subjects.

\section{Discussion}

The findings of the present study indicate that acute exercise may increase concentration of the end product of NO in systemic venous blood both in sedentary subjects and athletes. No difference was evident between the younger and older subjects, both in the basal and after-exercise 
Table 1. Characteristics of subjects

\begin{tabular}{llll}
\hline Groups & Age, years & Weight, kg & Height, cm \\
\hline Athletes & $21.5 \pm 2.88$ & $69.3 \pm 4.95$ & $180 \pm 5.35$ \\
Sedentary subjects & & & \\
$\quad$ Younger & $22.5 \pm 3.45$ & $71.3 \pm 6.12$ & $177 \pm 5.21$ \\
$\quad$ Older & $65.7 \pm 6.14$ & $69.2 \pm 4.27$ & $170 \pm 4.27$ \\
\hline
\end{tabular}

All values expressed as mean $\pm \mathrm{SD}$.

level, indicating that this change could not be influenced by age. The plasma increase of NO concentration observed after acute exercise suggests that even short periods of exercise can increase circulating NO. The higher basal plasma level of nitrite in the active subjects compared with sedentary groups indicates that the state of physical conditioning had an effect on resting NO concentration. The endogenous nitrovasodilator NO is continuously synthesized enzymatically by NO synthase from $L$-arginine and is released mainly from endothelial cells, although other cells are involved. The release of NO can be stimulated by various local and circulating factors. The exact mechanisms causing augmentation of NO production in athletes are not entirely clear. It is possible that physical training in athletes might be associated with an increased expression of the cNOS gene, resulting in a higher level of NO release compared with sedentary subjects.

Ex vivo experiments performed in animals have demonstrated an increase in constitutive NO synthase gene expression in exercised dogs relative to controls [16]. Our results did not distinguish the gene expression of different
Table 2. Changes in plasma $\mathrm{NO}_{2}^{-}$before and after exercise

\begin{tabular}{lll}
\hline Groups & $\mathrm{NO}_{2}^{-}, \mu \mathrm{mol} / 1$ & \\
\cline { 2 - 3 } & before exercise & after exercise \\
\hline $\begin{array}{l}\text { Athletes } \\
\text { Sedentary subjects }\end{array} \quad 41.40 \pm 6.06(\mathrm{n}=8)^{*}$ & $56.00 \pm 9.90(\mathrm{n}=8)^{\mathrm{a}}$ \\
$\quad$ & & \\
$\quad$ Oounger & $23.78 \pm 5.74(\mathrm{n}=12)$ & $44.73 \pm 6.48(\mathrm{n}=12)^{\mathrm{a}}$ \\
& $22.17 \pm 6.14(\mathrm{n}=12)$ & $45.88 \pm 9.84(\mathrm{n}=12)^{\mathrm{a}}$
\end{tabular}

All values expressed as mean \pm SD of the number of subjects shown in parentheses. Data were analysed by one-way analysis of variance followed by the Bonferroni t test.

$* \mathrm{p}<0.001$ when compared with inactive younger and older subjects; ${ }^{\text {a }} \mathrm{p}<0.05$ when compared before exercise.

NO synthase isoforms, and the type of isoform that contributes to the increase of $\mathrm{NO}$ in athlete group remains to be clarified. The cells normally express the constitutivetype NO synthase isoform and may even express the inducible isoform under pathological conditions.

The excessive production of NO by an inducible NO synthase has been implicated in pathological events. The factors that regulate the synthesis and release of endogenous NO by constitutive enzymes likely to be involved in a physiological process and by inducible enzymes that may underlie certain pathological events will thus be of importance to the understanding of pathophysiological mechanisms following repeated exposure to physical exercise and tissue integrity. It is possible that heavy physical training in athletes might be associated with the expression of inducible isoform. Further studies are certainly required to explore the effects of exercise training on NO synthase expression in endothelial cells.

\section{References}

1 Moncada S, Palmer RM, Higgs EA: Nitric oxide: Physiology, pathophysiology, and pharmacology. Pharmacol Rev 1991;43:109-142.

2 Hutcheson IR, Griffith TM: Central role of intracellular calcium stores in acute flow- and agonist-evoked endothelial nitric oxide release. Br J Pharmacol 1997;122:117-125.

3 Moncada S: The 1991 Ulf von Euler Lecture: The $L$-arginine:nitric oxide pathway. Acta Physiol Scand 1992;145:201-227.
4 Hester RL, Eraslan A, Saito Y: Differences in EDNO contribution to arteriolar diameters at rest and during functional dilation in striated muscle. Am J Physiol 1993;265(Heart Circ Physiol 34):H146-H151.

5 Hirai T, Visneski MD, Kearns KJ, Zelis R, Musch TI: Effects of NO synthase inhibition on the muscular blood flow response to treadmill exercise in rats. J Appl Physiol 1994;77:12881293.

6 Segal SS, Kurjiaka DT: Coordination of blood flow control in the resistance vasculature of skeletal muscle. Med Sci Sports Exerc 1995;27: 1158-1164.
7 Gilligan DM, Panza JA, Kilcoyne CM, Waclawiw MA, Casino PR, Quyyumi A: Contribution of endothelium-derived nitric oxide to exercise-induced vasodilation. Circulation 1994; 90:2853-2858.

8 Dyke CK, Proctor DN, Deitz NM, Joyner MJ: Role of nitric oxide in exercise hyperaemia during prolonged rhythmic handgripping in humans. J Physiol Lond 1995;488:259-265. 
9 Node K, Kitakaze M, Sato H, Koretsune Y, Katsube Y, Karita M, Kosaka H, Hori M: Effect of acute dynamic exercise on circulating plasma nitric oxide level and correlation to norepinephrine release in normal subjects. Am J Cardiol 1997;79:526-528

10 Wilson JR, Kapoor S: Contribution of endothelium derived relaxing factor to exercise-induced vasodilation in humans. J Appl Physiol 1993; 75:2740-2744.

11 Endo T, Imaizumi T, Tagawa T, Shiramoto M, Ando S, Takeshita A: Role of nitric oxide in exercise-induced vasodilation of the forearm. Circulation 1994;90:2886-2890.
12 Ambring A, Benthin G, Petersson AS, Jungersten L, Wennmalm A: Indirect evidence of increased expression of NO synthase in marathon runners, and upregulation of NO synthase activity during running. Circulation 1994;90:I137.

13 Gleim GW, Zeballos GA, Glace BW, Kaley G, Hintze TH: Venous nitric oxide metabolites decrease in highly trained endurance athletes during maximal exercise. Circulation 1994;90: I-659.

14 Green DJ, Fowler DT, O’Driscoll JG, Blanksby BA, Taylor RR: Endothelium-derived nitric oxide activity in forearm vessels of tennis players. J Appl Physiol 1996;81:943-948.
15 Gross S, Jaffe EA, Levi R, Kilbourn RG: Cytokine-activated endothelial cells express an isotype of nitric oxide synthase which is tetrahydrobiopterin-dependent, calmodulin-independent and inhibited by arginine analogs with a rank-order of potency characteristic of activated macrophages. Biochem Biophys Res Commun 1991;178:823-829.

16 Sessa WC, Pritchard K, Seyedi N, Wang J, Hintze TH: Chronic exercise in dogs increases coronary vascular nitric oxide production and endothelial cell nitric oxide synthase gene expression. Circ Res 1994;74:349-353. 